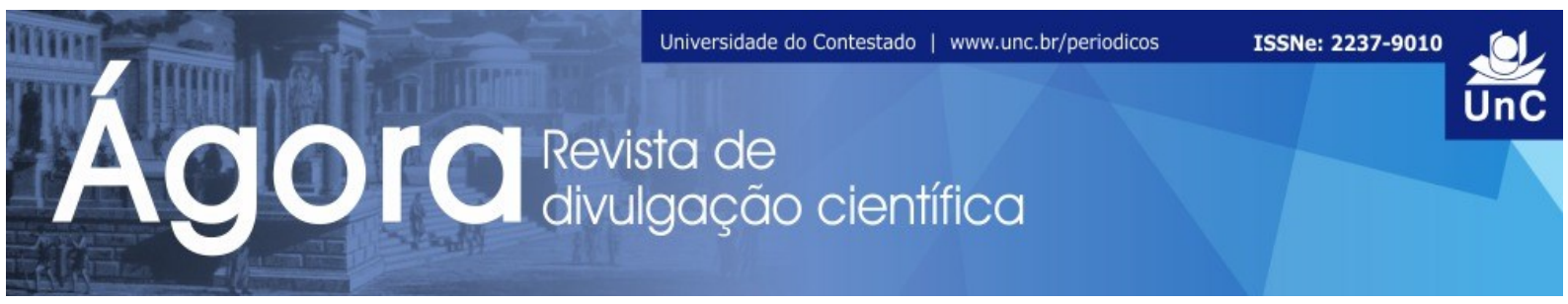

\title{
APLICAÇÃO DE MODELO MENTAL NA ANÁLISE AMBIENTAL DE UMA PEQUENA EMPRESA DO RAMO DE MÓVEIS PLANEJADOS
}

\author{
Andrei Giovani Maia ${ }^{1}$ \\ Julia Tontini
}

\begin{abstract}
RESUMO: Os desafios encontrados no ambiente organizacional, exigem dos gestores e empreendedores, a capacidade de análise ambiental para a definição de estratégias organizacionais. Em pequenas empresas a análise ambiental contribui para maior compreensão e melhor interação organizacional e possibilita a sobrevivência ou o crescimento da empresa diante da dinâmica do ambiente de mercado. Para compreender como a análise ambiental afeta as decisões e ações dos gestores e empreendedores, este artigo teve como objetivo principal, demonstrar a aplicação de modelo mental na análise ambiental de uma pequena empresa do ramo de móveis planejados de Palmeira das Missões/RS. Assim, realizou-se uma pesquisa descritiva, qualitativa, caracterizada como um estudo de caso. Como resultado, a análise do modelo mental definido pelo gestor da empresa de móveis planejados, mostrou que o ambiente de sua empresa é composto por concorrentes, pelo desempenho da agricultura regional, por oportunidades provenientes de novas construções e pela ameaça da crise econômica. Desta forma o estudo contribuiu com a identificação de fatores e variáveis ambientais que afetam o desempenho da empresa em sua atividade econômica.
\end{abstract}

Palavras-chave: Modelos Mentais. Análise Ambiental. Pequenas Empresas.

\section{APPLICATION OF MENTAL MODEL IN ANALYSIS ENVIRONMENT OF A SMALL COMPANY OF THE PLANNED FURNITURE BRANCH}

ABSTRACT: The challenges in the organizational environment, require the managers and entrepreneurs, an environmental analysis capacity for the definition of organizational strategies. In small companies, an environmental analysis contributes to greater understanding and better organizational interaction and allows the survival or growth of the company on the dynamics of the market environment. To understand how the environmental analysis affects the managers and entrepreneurs decisions and

\footnotetext{
${ }^{1}$ Doutor em Administração e Turismo pela Universidade do Vale do Itajaí (UNIVALI). Professor do curso de Ciências Econômicas da Universidade Federal de Santa Maria - Campus Palmeira das Missões/RS. Universidade Federal de Santa Maria. Campus Palmeira das Missões. Rio Grande do Sul. Brasil. E-mail: andreigiom@gmail.com

${ }^{2}$ Graduanda de Administração da Universidade Federal de Santa Maria - Campus Palmeira das Missões/RS. Universidade Federal de Santa Maria. Campus Palmeira das Missões. Rio Grande do Sul. Brasil. E-mail: ju-tontini@hotmail.com
}

Ágora: R. Divulg. Cient., v. 24, p. 1-22, 2019 (ISSNe 2237-9010) 
actions, this article had as main objective, demonstrate the aplication of the mental model on environmental analysis of a small company that produces planned furniture in Palmeira das Missões/RS. Thus, was held a descriptive, qualitative research, characterized as a case study. As a result, the analysis of the mental model, defined by the planned furniture company manager showed that the environment of his company is composed of competitors, the performance of regional agriculture, opportunities for new construction and the threat of the economic crisis. In this way, the study contributes with an identification of factors and variables that affect the performance of the company in its economic activity.

Keywords: Mental models. Environmental analysis. Small business.

\section{INTRODUÇÃO}

Muitas são as forças, fatores ou variáveis que podem afetar o funcionamento, o desempenho e os objetivos organizacionais e tais fatores estão relacionados à análise ambiental da organização feita pelo gestor. Este tipo de análise não está relacionado com o ambiente físico (natureza), mas sim, com o ambiente que as empresas estão inseridas e tem ligação estreita com a estratégia organizacional. A análise ambiental é uma ferramenta de gestão muito utilizada por grandes empresas, mas, não há qualquer restrição de uso por micro ou pequenas empresas.

Ao realizar uma análise ambiental o gestor da organização pode levar em consideração os modelos mentais, ferramenta útil na estruturação do conhecimento tácito dos envolvidos nessa análise, vez que auxiliam na compreensão de uma situação. Os modelos mentais descortinam as forças, fatores ou variáveis que influenciam o ambiente organizacional, tanto interno, quanto externo.

Este artigo teve por objetivo demonstrar a aplicação de modelos mentais na análise ambiental de uma pequena empresa do ramo de móveis planejados de Palmeira das Missões/RS. Para atingi-lo, usou-se de uma pesquisa descritiva, qualitativa, especificamente um estudo de caso, realizado em uma pequena empresa do setor de móveis, localizada no interior do Rio Grande do Sul, no ano de 2015.

Este artigo é composto por cinco seções a iniciar por esta introdução. A segunda seção tratou da revisão teórica que abordou os fundamentos da análise ambiental nas organizações, apresentou as analogias da administração sobre ambiente organizacional e os aspectos teóricos dos modelos mentais no estudo organizacional. A terceira seção apresentou os procedimentos metodológicos 
caracterizado em um estudo de caso qualitativo. Na quarta seção os resultados mostraram os principais fatores e variáveis identificados no mapa mental obtido na empresa estudada. Por fim, na última seção foram feitas as considerações finais do estudo.

\section{REVISÃO DA LITERATURA}

\subsection{A ANÁLISE AMBIENTAL NAS ORGANIZAÇÕES}

Em uma economia, as organizações estão em constante interação, visando a negociação, competição e definição de estratégias com o objetivo de sobrevivência ou maximização de seus resultados. Estas interações se ajustam, segundos fatores ou forças relacionadas às oportunidades emergentes ou às ameaças de mercado, que afetam diretamente as empresas e ocorrem dentro de determinada conjuntura econômica. Segundo Certo (2010, p. 28), "neste contexto, o ambiente organizacional é o conjunto de todos os fatores, tanto internos como externos, que podem influenciar o progresso obtido por meio da realização dos objetivos". Já na visão de Motta e Vasconcelos (2002, p. 378), "tradicionalmente, o meio ambiente é uma denominação atribuída ao conjunto de forças externas que influenciam o modo pelo qual as organizações funcionam e obtêm recursos".

Andrade e Amboni (2007) destacam as variáveis ambientais tecnológicas, legais, políticas, econômicas, demográficas, ecológicas e socioculturais, entre aquelas normalmente encontradas pelas organizações no ambiente externo, sendo que os componentes do ambiente operacional envolvem os clientes, fornecedores, concorrentes, grupos reguladores e os stakeholders. Além das variáveis ambientais apresentadas por Andrade e Amboni (2007), Luecke (2010) inclui ainda, entre os componentes ambientais, os produtos substitutos e destaca a possibilidade de existência de outros possíveis componentes ambientais não percebidos pelas organizações.

A compreensão do ambiente e a definição de estratégias organizacionais dependem de informações provenientes de sistemas com bases de dados devidamente organizados e confiáveis. Para Drucker (2001), o que a maioria das empresas precisa saber sobre o ambiente externo só está disponível em fonte externa, 
ou seja, em bases de dados externas à empresa. Conforme Certo (2010, p. 28), "as organizações devem constantemente reunir os dados relacionados com importantes fatores ambientais e considerar suas implicações". Andrade e Amboni (2007, p. 29) esclarecem que "embora alguns ambientes ainda possam ser relativamente simples e estáveis, outros tendem a ser muito mais complexos e dinâmicos por natureza". Em um ambiente organizacional externo, as informações se tornam mais relevantes à medida que há o aumento do nível de complexidade do ambiente organizacional.

Nos termos de Drucker (2001, p. 128), "seja qual for o método adotado, a necessidade de informação sobre o ambiente externo, de onde é provável que surjam as maiores ameaças e oportunidades, vai se tornar cada vez mais urgente". Com as informações obtidas no ambiente externo, a análise ambiental tende a influenciar as decisões estratégicas das organizações que se refletirão nos mercados. Certo (2010) explica que a análise ambiental é o processo de monitoramento do ambiente organizacional para identificar as oportunidades e os riscos atuais e futuros que possam influenciar a capacidade da empresa de atingir seus objetivos, sem a existência de uma forma ideal de se realizar tal análise. De acordo com Donaires (2006, p. 21), "o ambiente, portanto, inclui um universo de possibilidades extremamente abrangente". Este universo de possibilidades permite o desenvolvimento de perspectivas ou teorias mais deterministas ou subjetivistas, conforme distintas interpretações do ambiente organizacional.

Em outras palavras, a existência e a estrutura do ambiente competitivo são significativos para explicar as decisões tomadas relativamente ao marketing, pesquisa e desenvolvimento, produção, finanças, planejamento estratégico, distribuição, entre outros (NELLIS; PARKER, 2003). Em uma perspectiva microeconômica, é possível identificar a estrutura do ambiente e seu nível de competitividade. Para que um empreendedor possa determinar a estrutura do ambiente em que sua organização está inserida é necessária a identificação de três características básicas de mercado, entre as quais, destacam-se: o número e o tamanho das empresas, o grau de diferenciação dos produtos existentes e a força das barreiras impostas à entrada e à saída enfrentadas pelos participantes potenciais do mercado (MANKIW, 2013, PINDYCK; RUBINFELD, 2010, NELLIS; PARKER, 2003). De acordo com estas características, é possível classificar os mercados em estruturas como monopólio, 
oligopólio, concorrência monopolística ou pura, de acordo com o grau de concentração econômica das organizações.

Para um posicionamento estratégico organizacional em mercados competitivos a análise ambiental é essencial, pois permite a identificação e a avaliação de direcionadores externos de mudança que afetem a empresa (NELLIS; PARKER, 2003). A análise ambiental contempla tanto uma análise macroambiental, relacionada à identificação de tendências externas provenientes de fatores econômicos, políticos, sociais e tecnológicos que afetam a empresa, quanto à análise microambiental que enfoca os aspectos do ambiente competitivo da empresa em uma perspectiva industrial ou de mercado (NELLIS; PARKER, 2003).

Mesmo que as pequenas ou microempresas tenham suas demandas bem definidas ou consolidadas, conhecer a estrutura de mercado em que a empresa está inserida, deve fazer parte de sua estratégia, pois, sempre existe o risco de concorrência das organizações com maior poder de mercado. Além disso, com uma análise micro e macroambiental é possível identificar variáveis que influenciam os negócios da empresa, permitindo ao empreendedor mapear sua concorrência, definir seu tamanho, conhecer seus produtos e avaliar seu poder de mercado entre outras importantes forças ambientais não controláveis.

\subsection{ANALOGIAS DA ADMINISTRAÇÃO SOBRE AMBIENTE ORGANIZACIONAL}

Nas teorias das organizações é possível encontrar diversas concepções ou analogias do ambiente organizacional. Tais analogias se refletem na construção teórica das correntes ou escolas do pensamento estratégico e representam, em sua essência, as possibilidades e restrições dos processos de elaboração de estratégia. Morgan (2007) salienta a importância dos paradigmas como visões da realidade social. Com base nas visões da realidade social, o autor se utiliza de analogias ou metáforas para representar as bases das escolas de pensamento na teoria das organizações (MORGAN, 2007). Sob a influência das analogias do ambiente organizacional, a formulação de estratégia pode ser representada por escolas do pensamento estratégico com suas relevantes contribuições e limitações (MINTZBERG; AHLSTRAND; LAMPEL, 2010). 
Um importante debate na Teoria Organizacional envolve a discussão da organização como parte de um sistema aberto e a visão objetiva ou subjetiva do ambiente pelo estrategista. A visão objetiva do ambiente está associada ao paradigma tradicional conhecido como funcionalista. Conforme Morgan (2007), o paradigma funcionalista está baseado no pressuposto da existência concreta e real da sociedade cujo caráter sistêmico busca produzir um estado ordenado e regulado. Assim, na visão dos funcionalistas, as organizações seriam objetos tangíveis, concretos e objetivos (VERGARA; CALDAS, 2007). O planejamento estratégico é um claro exemplo de abordagem estratégica com forte viés objetivista baseado no controle e na previsão.

$\mathrm{Na}$ perspectiva subjetiva do ambiente está o paradigma interpretativista, que segundo Morgan (2007) se baseia na visão de mundo social ontologicamente duvidosa em que a realidade social é resultado das experiências subjetivas e intersubjetivas dos indivíduos. Neste sentido, as organizações seriam processos que emergem das ações individuais e interações intencionais de pessoas que buscam compreender seu mundo (VERGARA; CALDAS, 2007).

Entre os principais avanços na analogia do ambiente organizacional destacase a classificação do ambiente externo, apresentada por Smircich e Stubbart (1985). Ao classificarem o ambiente externo em uma perspectiva objetiva, percebida ou construída, Smircich e Stubbart (1985) fazem um enquadramento epistemológico definido a partir da forma como o estrategista ou os tomadores de decisão veem o ambiente organizacional. Nesta classificação a visão de um ambiente objetivo resulta em estratégias mais prescritivas e funcionalistas e, a visão ambiental subjetiva influencia no processo de elaboração de estratégias mais descritivas e interpretativas.

$\mathrm{O}$ ambiente objetivo sustenta-se em uma epistemologia funcionalista cuja realidade se apresenta como um elemento concreto, formal, determinado e controlado pelas organizações. Conforme Maciel, Weymer e Augusto (2012), as organizações que possuem poder sobre o ambiente são capazes de modelar seu contexto e, aquelas sem este poder acabam sendo modeladas pelo ambiente. É forte a influência do conceito de homem econômico perante a concepção objetiva do ambiente, pois o indivíduo é visto como um ser simples, previsível e controlável e os resultados organizacionais podem ser otimizados. Nesta direção, destacam-se as escolas mais tradicionais da estratégia por seu caráter prescritivo e tangível do ambiente como a escola do design, do planejamento e do posicionamento estratégico (MINTZBERG; 
AHLSTRAND; LAMPEL, 2010). Neste tipo de ambiente as ferramentas que permitem análises quantitativas como a estatística ou a matemática são essenciais nas organizações. Para Lobato (2003) essas escolas marcaram quatro importantes fases da evolução do pensamento estratégico. As duas primeiras fases foram marcadas pelas escolas do planejamento financeiro e de longo prazo, a terceira fase teve como marco teórico a escola do planejamento estratégico que contemplou a tradicional análise SWOT com a identificação das forças, fraquezas, oportunidades e ameaças e a quarta fase com a escola da administração estratégica com destaque para as cinco forças competitivas da indústria de Porter (LOBATO et al., 2003). Baseadas no processo racional de formulação estratégica, essas escolas são conduzidas pelo controle, previsibilidade e projeção de cenários, considerando ambiente de negócios.

Apesar de também se caracterizar dentro da epistemologia funcionalista, o ambiente percebido reconhece as limitações em se definir a amplitude ambiental pelas organizações e indivíduos. Evidencia-se a influência dos estudos Herbert Simon (1971, 1978), principalmente devido às limitações humanas em tomar decisões que levem aos resultados otimizados e às informações imperfeitas obtidas no ambiente organizacional. Maciel, Weymer e Augusto (2012, p. 82) salientam que, "interessa a essa perspectiva verificar quão equivocadas ou fidedignas parecem ser as percepções dos estrategistas em relação ao ambiente concreto, bem como suas consequências". Ao seguir as escolas apresentadas por Mintzberg, Ahlstrand e Lampel (2010), aquelas que se aproximam da abordagem do ambiente percebido são a escola cognitiva, a ambiental, a cultural e a escola de poder. Com base nas fases da evolução do pensamento estratégico abordado por Lobato et al. (2003), a escola da gestão estratégica marcou a quinta fase da evolução do pensamento estratégico e, em geral, se aproxima mais do ambiente percebido dado seu enfoque sistêmico e de equilíbrio entre o ambiente interno e externo da organização.

A concepção do ambiente construído está sustentada em uma epistemologia interpretativista em que o estrategista constrói o ambiente e as organizações a partir de sua compreensão de mundo (MINTZBERG; AHLSTRAND; LAMPEL, 2010). Os processos de construção do ambiente pelos estrategistas influenciam a construção social do ambiente, pois darão base às compreensões individuais a partir de suas próprias experiências. As escolas de estratégia que estão mais próximas da analogia do ambiente construído são a escola do aprendizado, a escola empreendedora, de 
configuração, e novamente, a escola cognitiva que segundo Mintzberg, Ahlstrand e Lampel (2010), pode considerar o ambiente, também como uma construção social. Nesta direção, Lobato et al. (2003) salientam que dada a complexidade e a imprevisibilidade dos novos cenários, emerge a escola da gestão estratégica competitiva que assume a forma de um processo de aprendizado de longo prazo.

Quadro 1 - O ambiente organizacional e as escolas de estratégia

\begin{tabular}{|l|l|l|}
\hline \multicolumn{1}{|c|}{ Ambiente Objetivo } & \multicolumn{1}{c|}{ Ambiente Percebido } & \multicolumn{1}{c|}{ Ambiente Construído } \\
\hline Escola do Design & Escola Ambiental & Escola Cognitiva (2) \\
\hline Escola do Planejamento & Escola Cultural & Escola de Aprendizado \\
\hline Escola do Posicionamento & Escola de Poder & Escola Empreendedora \\
\hline & Escola Cognitiva (1) & Escola de Configuração \\
\hline
\end{tabular}

Fonte: Adaptado de Smircich e Stubbart (1985) e Mintzberg, Ahlstrand e Lampel (2010).

Diante das analogias do ambiente organizacional, a concepção do ambiente externo da organização pelos estrategistas mudou e influenciou as dez escolas de estratégia que passaram de uma perspectiva ambiental mais determinista (funcionalista) para uma perspectiva mais compreensiva (interpretativista). Conforme Crainer e Dearlove $(2014$, p. 112) "o problema é que na prática, o pensamento moderno sobre estratégia não se encaixa perfeitamente em uma ou outra das 10 escolas". O ambiente externo da organização envolve um elevado nível de complexidade que em sua dinâmica não pode se resumir às restrições teóricas da estratégia.

Barbosa et al. (2018) apontam as ferramentas visuais e a própria visualização da informação, sendo maneiras eficazes para compreender o ambiente e resolver melhor os problemas. Souza e Ventura (2017) corroboram afirmando que a realização de um planejamento estratégico é bem compreendido quando visualiza-se e entendese o todo. Assim, os métodos visuais são importantes no aprimoramento de estratégias para as empresas. Prova disso, é a matriz de Ansoff (1990) que é formada pelas dimensões de mercados e produtos, permitindo a análise das oportunidades da empresa por meio de quatro possibilidades estratégicas, penetração de mercado, desenvolvimento de mercado, diversificação e desenvolvimento de produtos.

Para Crainer e Dearlove (2014) o desenvolvimento e a evolução da estratégia se dá por vários impulsos conflitantes, colaboração, competição, criatividade, repaginação de antigas ideias e por novos conceitos emergentes. Portanto, a concepção de um ambiente organizacional construído e dinâmico está levando o 
pensamento estratégico para novas fronteiras teóricas e práticas que exigem maior compreensão da interação entre a organização e seu ambiente.

Entre as possíveis ferramentas que as empresas podem usar na compreensão destas interações estão os modelos mentais construídos pelos estrategistas ou empreendedores. Entre os modelos mentais estão os mapas mentais que permitem identificar as principais variáveis ambientais externas e internas que tendem a influenciar a organização. O item a seguir aborda os fundamentos dos modelos e mapas mentais e procura mostrar sua relevância na elaboração de estratégias organizacionais.

\subsection{MODELOS MENTAIS NO ESTUDO ORGANIZACIONAL: DEFINIÇÕES E APLICAÇÕES}

O termo modelo mental vem, gradativamente, sendo incorporado ao cotidiano organizacional. Esse modelo auxilia nas representações diversas sobre o mundo, servindo para a interpretação de uma realidade atual. O conceito sobre os modelos mentais surgiu em 1943 com Kenneth Craik, um psicólogo escocês que acreditava que o ser humano exprime os elementos do ambiente em que vive por meio destes modelos (TONI; MILAN; HEXSEL, 2007). O termo modelo mental, provavelmente tenha surgido com a publicação de livros de Johnson-Laird, em 1983, autor este que o definia como a apresentação interna ou externa de informações que corresponde, analogamente, ao que está sendo representado (ERROBIDART et al., 2013).

Johnson-Laird (1983, apud MOREIRA, 1996, p. 220) aponta ainda três tipos de representações mentais: as representações proposicionais, os modelos mentais e as imagens mentais. O primeiro diz respeito ao sentido do discurso; o segundo serve para relatar uma situação, incluindo os objetos e o conhecimento envolvido; já as imagens representam como as coisas irão ser vistas particularmente por um observador.

Para Jonhson-Laird (1983, apud SOUZA; MOREIRA, 2000) os modelos mentais são representações relevantes que permitem 0 entendimento do conhecimento humano. Portanto, com os modelos mentais torna-se possível fazer uma descrição essencial de um fenômeno ou situação, compreender seu funcionamento e suas características. Ao analisarem uma situação as pessoas 
Aplicação de modelo mental na análise ambiental de uma pequena empresa do ramo de móveis planejados

desenvolvem modelos mentais lógicos na busca por explicações ou compreensões vivenciadas em seu ambiente social e organizacional.

Jonhson-Laird (1983, apud MOREIRA, 1996, p. 202-203), aponta uma série de princípios que caracterizam, e ao mesmo tempo, identificam os limites dos modelos mentais, os quais podem ser vistos no quadro 2:

Quadro 2 - Princípios dos modelos mentais de Jonhson-Laird

\begin{tabular}{|l|l|}
\hline $\begin{array}{l}\text { Princípios dos modelos } \\
\text { mentais }\end{array}$ & \multicolumn{1}{c|}{ Definição } \\
\hline $\begin{array}{l}\text { Princípio da } \\
\text { computabilidade }\end{array}$ & $\begin{array}{l}\text { São procedimentos efetivos (reais) que podem ser executados por } \\
\text { uma máquina. }\end{array}$ \\
\hline Princípio da finitude & São finitos, ou seja, representam algo que possui um fim. \\
\hline $\begin{array}{l}\text { Princípio do } \\
\text { construtivismo }\end{array}$ & $\begin{array}{l}\text { São construídos a partir de elementos fundamentais organizados em } \\
\text { um sistema que representa algo. }\end{array}$ \\
\hline Princípio da economia & $\begin{array}{l}\text { São finitos, mas após um determinado tempo o pensamento acerca } \\
\text { dele muda. Passando a possuir novas ideias, desse modo, há um } \\
\text { número infinito de possíveis estado de coisas. }\end{array}$ \\
\hline $\begin{array}{l}\text { Princípio da não- } \\
\text { indeterminação }\end{array}$ & $\begin{array}{l}\text { Está relacionado com a ideia de que, se há um alto crescimento de } \\
\text { interpretações sobre um objeto, então, na prática, deixará de ser } \\
\text { considerado um modelo mental. }\end{array}$ \\
\hline $\begin{array}{l}\text { Princípio da } \\
\text { predicabilidade }\end{array}$ & $\begin{array}{l}\text { Dois conceitos distintos utilizados em um modelo mental devem } \\
\text { possuir algo em comum, que se intersecta. }\end{array}$ \\
\hline Princípio do inatismo & $\begin{array}{l}\text { A construção de um modelo mental não deve ser da experiência, mas } \\
\text { de algo real, inato. }\end{array}$ \\
\hline $\begin{array}{l}\text { Princípio do número finito } \\
\text { de primitivos conceituais }\end{array}$ & $\begin{array}{l}\text { Os primitivos conceituais estão submetidos a representar experiências } \\
\text { e habilidades. Esse princípio mostra que há inúmeras maneiras de } \\
\text { representar uma palavra, entretanto, cada palavra ou objeto possui } \\
\text { uma única característica própria. }\end{array}$ \\
\hline $\begin{array}{l}\text { Princípio da identidade } \\
\text { estrutural }\end{array}$ & $\begin{array}{l}\text { A estrutura dos modelos mentais é igual às estruturas do estado de } \\
\text { coisas, então cada modelo mental e suas relações estruturais deve ter } \\
\text { um papel característico. }\end{array}$ \\
\hline
\end{tabular}

Fonte: adaptado de Jonhson-Laird (1983, apud MOREIRA, 1996, p. 202-203).

Assim, é importante salientar que, indiferente da forma ou das características utilizadas, na construção de um modelo mental o objetivo principal é saber que as empresas de sucesso são aquelas que melhor desenvolvem modelos mentais a partir do conhecimento que os indivíduos possuem. Esses modelos aperfeiçoam e inovam o negócio, já que eles têm o propósito de beneficiar todo o ambiente organizacional.

Como citado anteriormente, por meio de modelos mentais pode-se construir a percepção sobre algo e é a partir disto, que muitas vezes as pessoas tomam decisões, como consequência do que elas pensam. Ao mesmo tempo, esses modelos são mutáveis - pois as ideias dos indivíduos modificam-se constantemente - e estão sempre em construção para se adaptarem as respostas do ambiente. Nesta lógica Moreira (1996, p. 195), afirma que os "[...] modelos mentais são como blocos de 
construção cognitivos que podem ser combinados e recombinados, conforme necessário". Entretanto, é importante que sempre a ênfase esteja em captar a essência da situação, seja ela mutável ou não.

Para a construção de uma modelo metal é necessário que se faça uma análise, bem como uma observação detalhada sobre algo. No caso deste artigo, busca-se um diagnóstico criterioso sobre o ambiente de uma organização. $O$ aspecto deste modelo está relacionado a uma estrutura, ou seja, um sistema integrado. De acordo com Maximiano (2008, p. 40) sistema "[...] é um conjunto de partes ou elementos que formam um todo unitário ou complexo". Assim, salienta-se que os modelos mentais estão diretamente relacionados com o conceito de sistema, já que os dois formam um conjunto de informações que possuem um propósito.

Com base nos estudos de Toni, Milan e Hexsel (2007), os modelos mentais podem ainda ser caracterizados como uma construção sistêmica, podendo ser configurada a partir de um conjunto de elementos funcionais, simbólicos, cognitivos e emocionais. Os elementos funcionais expressam os aspectos de utilidade da organização, como porte, produtos, infraestrutura, mercado no qual está inserido, etc. Já, os elementos simbólicos são avaliados pelo que eles significam para as pessoas. Os elementos cognitivos são construções mentais sobre determinados objetos; são eles que irão trazer informações e significado ao objeto. E, por fim, os elementos emocionais significam o estado afetivo (positivo ou negativo) que o indivíduo leva sobre a organização. É dessa maneira que o empreendedor obtém suas conclusões, a partir das representações coletivas dos indivíduos e, assim, constrói o modelo mental mais adequado a sua empresa.

O desempenho organizacional, de acordo com Neely, Gregory e Platts (1995, apud CARVALHO, 2011), está atrelado ao processo de quantificar uma ação por meio de sua eficiência e eficácia. No entanto, com relação ao desempenho organizacional a partir de modelos mentais, as associações se dão com os fatores internos e externos. Na concepção de Toni e Milan (2008 apud TONI et al. 2014, p. 36-37) há uma lista de fatores que compõem os modelos mentais dos empreendedores e os fatores que podem justificar parcialmente o desempenho organizacional, sendo: 
Aplicação de modelo mental na análise ambiental de uma pequena empresa do ramo de móveis planejados

Quadro 3 - Fatores componentes dos modelos mentais dos empreendedores

\begin{tabular}{|l|l|}
\hline Fatores componentes & \multicolumn{1}{c|}{ Características } \\
\hline Conhecimentos & $\begin{array}{l}\text { Riscos, aspectos técnicos, aspectos do ambiente, experiência anterior, } \\
\text { predisposição para aprender. }\end{array}$ \\
\hline Habilidades emocionais & $\begin{array}{l}\text { Autoestima, autoconfiança, fluência com emoções, aceitação da } \\
\text { incerteza e inteligência emocional. }\end{array}$ \\
\hline Mente linear & $\begin{array}{l}\text { Inteligência linear, organização, planejamento, liderança, orientação } \\
\text { para o poder. }\end{array}$ \\
\hline Relacionamento & $\begin{array}{l}\text { Relacionamentos com colaboradores, clientes e fornecedores, } \\
\text { reconhecimento do outro, respeito pelo outro, valorização do outro, } \\
\text { aceitação das diferenças, dar e receber, justiça e misericórdia. }\end{array}$ \\
\hline Comunicação e ética & Orientação para a comunicação e padrões éticos. \\
\hline Missão e estratégia & $\begin{array}{l}\text { Prática com cenários futuros, pensamento sistêmico, pensamento } \\
\text { intuitivo e competência. }\end{array}$ \\
\hline Criatividade & $\begin{array}{l}\text { Comportamento inovador, iniciativa, deteç̧ão de problemas, detecção } \\
\text { de oportunidades e inovação. }\end{array}$ \\
\hline Vocação & $\begin{array}{l}\text { Força de vontade, clareza de propósito, orientação por princípios e } \\
\text { orientação evolutiva. }\end{array}$ \\
\hline
\end{tabular}

Fonte: adaptado de Toni e Milan (2008 apud TONI et al. 2014, p. 36-37).

É importante, novamente, ressaltar que mesmo que os modelos mentais possam apresentar teorias relativamente complexas, são eles que irão moldar a forma de agir da organização. Por isso, é imprescindível compreendê-lo na sua forma mais simples e notar sua capacidade essencial de representar um ambiente, seu formato, características e todo o seu entorno. Muitas vezes, o desempenho positivo, ou negativo, de uma empresa tem relação direta com os modelos mentais utilizados (em alguns casos, indiretamente) pelos seus empreendedores (CIDADE et al., 2011). Para alcançar o sucesso desejado, é necessário que todos os envolvidos, tanto gestores quanto colaboradores, trabalhem em prol do desenvolvimento organizacional.

Assim, nota-se a importância da adoção dos modelos mentais dentro das organizações, já que eles têm a capacidade de descrever todo o ambiente, além de, desencadear mudanças na forma como os indivíduos trabalham e interagem dentro da empresa. E, isso ocorre devido à complexidade das organizações humanas, que buscam sempre melhorar e solucionar problemas administrativos.

\section{PROCEDIMENTOS METODOLÓGICOS}

Este trabalho caracterizou-se como uma pesquisa qualitativa que utilizou a estratégia de estudo de caso. A pesquisa qualitativa é um processo de reflexão que se refere a questões muito particulares da realidade que não podem ser quantificados (OLIVEIRA, 2007; MINAYO, 2009). Diante do perfil qualitativo desta pesquisa, optou- 
se pelo estudo de caso como estratégia de pesquisa por permitir a compreensão do ambiente organizacional. Segundo Oliveira (2007) "o estudo de caso é um método abrangente que permite se chegar a generalizações amplas baseadas em evidências e que facilita a compreensão da realidade".

A realização do estudo de caso contou com a aplicação de uma entrevista junto a um empresário em meados de 2015, com o objetivo de mostrar a aplicação do mapa mental na análise do ambiente externo de uma pequena empresa do ramo de móveis planejados do Município de Palmeira das Missões/RS. A entrevista está relacionada a uma conversa entre um ou mais entrevistados e o entrevistador e tem como objetivo levantar informações pertinentes para um objeto de pesquisa (MINAYO, 2009). A entrevista com roteiro semiestruturado foi realizada em um contexto de crise econômica no Brasil, e a escolha da empresa do ramo de móveis planejados, baseouse na sensibilidade econômica deste setor, dada a sua possível dependência em relação ao desempenho do setor agrícola do noroeste do Rio Grande do Sul. A partir da entrevista, os autores elaboraram o mapa mental da compreensão do ambiente externo do empresário que atua no ramo de móveis e puderam mostrar as principais variáveis envolvidas nas decisões estratégicas da pequena empresa.

\section{ANÁLISE DOS RESULTADOS E DISCUSSÕES}

Para obter-se um entendimento e análise sobre a perspectiva do ambiente interno e externo de pequenas empresas, realizou-se uma entrevista junto ao empresário (proprietário) da empresa de pequeno porte que produz e vende móveis planejados. O entrevistado desenvolve sua atividade como gerente comercial e é o responsável pela tomada de decisões estratégicas da empresa estudada. A partir das respostas obtidas durante a entrevista, foi possível construir o mapa mental da visão de ambiente interno e externo da empresa. O mapa mental permitiu identificar os principais fatores e elementos que são levados em consideração pelo empresário em suas decisões estratégicas. 


\subsection{AMBIENTE INTERNO E EXTERNO: A LEITURA DOS EMPREENDEDORES}

A visão do entrevistado sobre o ambiente interno está relacionada aos aspectos que dizem respeito àquilo que a empresa consegue influenciar, ou seja, refere-se às questões que são de domínio dos gestores e seu quadro de colaboradores. Ele considera como o ambiente interno tudo aquilo que está "dentro da empresa". Entre os principais fatores que compõem o ambiente interno da empresa de pequeno porte estão: a produção realizada por profissionais qualificados e equipamentos de precisão, as vendas realizadas por vendedores experientes em loja física com mostruário diversificado, marketing promocional por redes sociais e a entrega com total cuidado no transporte e montagem dos móveis.

Já com relação ao ambiente externo, o gerente comercial menciona que o tal ambiente é composto pelos concorrentes, fornecedores e clientes, sendo estes últimos os principais motivos da existência da empresa. O mapeamento do ambiente interno e externo das organizações possibilita ao gestor ter uma visão ampla sobre a empresa e a competitividade em seu mercado. O acompanhamento do ambiente externo possibilita definir o comportamento dos concorrentes diante do mercado de trabalho, salienta o entrevistado.

$\mathrm{Na}$ concepção de Barney e Hesterly (2007) a análise do ambiente interno ocorre através da identificação dos pontos fortes e fracos (controláveis) que internamente afetam a organização, mas o diagnóstico do ambiente externo ocorre através da identificação das oportunidades e ameaças, que são variáveis que a empresa não tem controle. Uma abordagem de análise SWOT pode contribuir na identificação das variáveis e fatores a serem usados no mapeamento mental do ambiente da empresa. $\mathrm{O}$ ambiente externo pode afetar negativamente uma empresa. Um dos motivos citados pelo entrevistado é a condição climática que afeta diretamente a agricultura e reduz a demanda do público-alvo da empresa que são os agricultores.

De acordo com o entrevistado, o principal público consumidor de seus produtos, são agricultores, assim, se estes obtêm sucesso em sua atividade produtiva, tal resultado se reflete em lucros para a empresa de móveis planejados, entretanto, no caso de baixo desempenho da atividade agrícola, sua empresa sente o impacto negativo com a queda nas vendas. Além disso, outro fator negativo que a empresa enfrenta é a crise econômica que afeta o país, reduzindo muito a demanda, o que 
provoca forte queda nas vendas desse tipo de produto. Porém, até pouco tempo, as empresas deste ramo vivenciaram um período favorável devido às políticas de incentivo do governo à construção civil, consumo de produtos da linha branca e de mobiliários. Apesar de salientar o momento atual recessivo da economia e de seu setor produtivo, o entrevistado também destacou que o ramo de móveis planejados teve um mercado aquecido com forte crescimento nas vendas, o que ocorre geralmente nos meses após a safra agrícola, a partir do mês de maio.

Com o surgimento de problemas que ameaçam a existência da empresa exigem dos gestores estratégias de adequação e ajustes diante do mercado. Além disso, as empresas precisam enfrentar a concorrência que torna o ambiente mais competitivo. Na visão do entrevistado, para solucionar estes problemas, é necessário possuir funcionários capacitados e treinados para bem atender os clientes e, que seus produtos e serviços possuam um preço adequado e qualidade de alto padrão. Entretanto, o entrevistado destacou que não se utiliza de ferramentas específicas de análise de ambiente externo e reconhece que o mapa mental poderia auxiliá-lo neste processo.

Nota-se assim, que o entrevistado faz uma leitura empírica do ambiente, não se apoiando em alguma metodologia específica e tampouco faz menção à possibilidade de sistematizar a leitura do ambiente. Isso implica desvios que tendem a afetar a tomada de decisões estratégicas e consequentemente o desempenho da empresa diante do mercado. Como o ambiente não é mapeado, o gestor toma decisões que buscam resolver problemas provenientes de situações imprevistas, ou seja, a empresa não se antecipa às situações ambientais externas ou mesmo internas.

Questionado sobre o entendimento de estratégia, o entrevistado diz que estratégia representa o modo como a empresa se insere no mercado, conquista novos clientes e como os fideliza. Para o entrevistado, as estratégias são elaboradas pela equipe, que é bem treinada, qualificada e focada para atingir objetivos. Na concepção de Mintzberg (1994, apud ZACCARELLI, 2000, p. 41), "estratégia é um referencial, um guia, para auxiliar os executivos na solução de certos problemas”. Constata-se assim, a importância de possuir uma estratégia em qualquer ambiente organizacional, para solucionar problemas e atingir os objetivos estabelecidos. Diante da resposta obtida, pode-se observar o distanciamento entre o que os teóricos defendem sobre o 
uso estratégico das informações para antecipação às oportunidades e ameaças ambientais e o posicionamento meramente reativo ao ambiente da empresa.

Diante do exposto, observou-se a ausência de abordagens estratégicas consistentes que permitam o gestor visualizar cenários, prever situações e redefinir os rumos de sua empresa. Ao delegar a análise do ambiente externo o empresário mostra que seu foco está no ambiente interno e dá pouca atenção ao ambiente externo. Além disso, o empresário (gestor) não utiliza métodos ou modelos efetivos de mapeamento e análise de ambiente externo. Dada a importância dos modelos mentais para as organizações, Andrade et al. (2006, p. 317) salienta que "desenvolver a capacidade de desafiar modelos mentais envolve o emprego de técnicas, inovações institucionais e princípios operacionais". Assim, tanto gestores, quanto colaboradores devem desenvolver métodos de análise de ambiente interno e externo que contribuam para o sucesso organizacional. Com esta perspectiva, se introduz a próxima seção, na qual se propõe o desenho do mapa mental com base na visão do gestor.

\subsection{MAPA MENTAL ELABORADO A PARTIR DA VISÃO ESTRATÉGICA DO EMPRESÁRIO}

A partir da entrevista com o empresário sobre a sua visão do ambiente externo da empresa de móveis planejados, pode-se construir um mapa mental. A Figura 1 apresenta o mapa mental elaborado a partir da visão de um empresário que administra uma pequena empresa do ramo de móveis planejados do Município de PM / RS. 
Figura 1 - Mapa mental do empresário de uma pequena empresa de móveis planejados

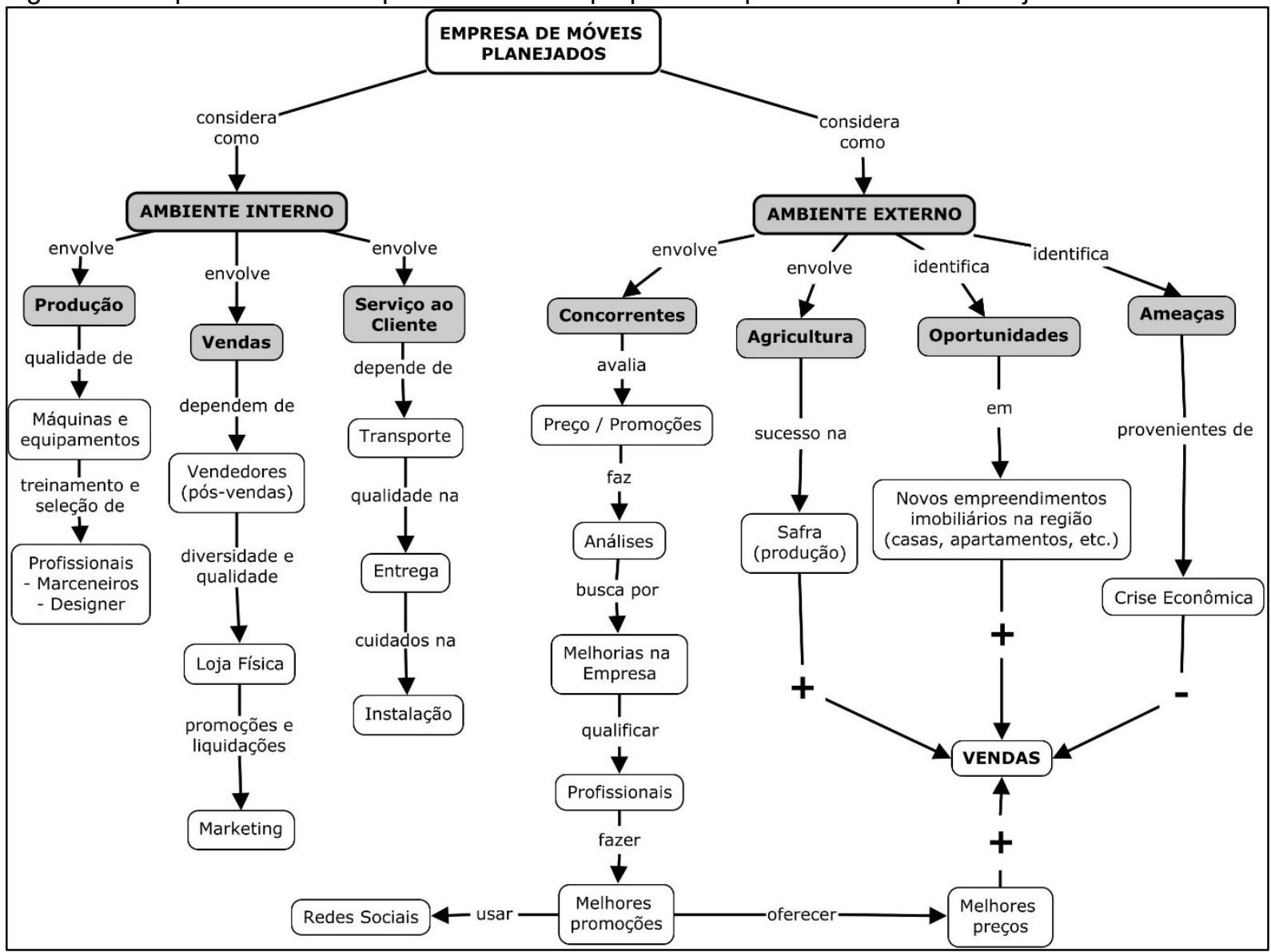

Fonte: elaborado pelos autores.

Notou-se assim, que existem quatro principais fatores determinantes para a empresa em questão: os concorrentes, a agricultura, oportunidades e ameaças. Com relação aos concorrentes pode-se observar que é constante a análise feita em relação aos mesmos, desde preço e promoções. Dessa maneira, a empresa buscou capacitar e treinar seus 10 funcionários, além de, investir em propagandas em redes sociais e melhorar o preço dos produtos. Salienta-se que o treinamento caracteriza as estratégias do ambiente aprendido nos termos de Mintzberg, Ahlstrand e Lampel (2010). Em relação a perspectiva ambiental que envolve oportunidades e ameaças destacadas pelo entrevistado, há uma forte aproximação da análise SWOT que conforme Lobato et al. (2003), faz parte das escolas de estratégia que avaliam objetivamente o ambiente.

Como citado anteriormente, um fator determinante ao sucesso de vendas da empresa são os agricultores, público que mais compra. Por este motivo, salienta-se a importância da condição climática, para ambas as partes se favorecerem. Além disso, um dos fatores externos positivos a empresa, é que há grandes oportunidades com Ágora: R. Divulg. Cient., v. 24, p. 1-22, 2019 (ISSNe 2237-9010) 
relação à construção de imóveis, como apartamentos e casas, consequentemente, há maior venda de produtos para estes ambientes.

Porém, com relação às ameaças externas a empresa, estaria a crise econômica, com baixo índice de venda de produtos, conforme representação pelo símbolo "-" (menos). Já os outros aspectos, como se pode perceber no mapa mental com o símbolo "+" (mais), alavancam as vendas da empresa.

Como pode-se observar no mapa mental construído a partir das respostas obtidas na entrevista com o empresário do ramo de móveis planejados, a visão do ambiente externo à empresa apresenta um grau de simplicidade, mas, mostra quais são as principais variáveis a serem levadas em consideração pelos gestores ao definirem suas estratégias de atuação neste mercado. Entretanto, em termos teóricos há certa distância das classificações apresentadas por Mintzberg, Ahlstrand e Lampel (2010) e a perspectiva ambiental do entrevistado. Há uma constante oscilação de ideias do entrevistado que em certos momentos apresenta uma perspectiva mais objetiva do ambiente, em outros, mostra sua perspectiva percebida do ambiente, o que indica desconhecimento de padrões teóricos coesos e consistentes sobre estratégia. A aplicação do mapa mental contribuiu na observação do conhecimento do estrategista sobre os fundamentos teóricos da estratégia, assim como na identificação de possíveis técnicas de análise e na constatação da amplitude e do nível de profundidade que o estrategista apresenta em suas abordagens ambientais ao longo do tempo.

\section{CONSIDERAÇÕES FINAIS}

Estes resultados reforçam que o gestor da empresa analisada, desconhece as ferramentas teóricas de gestão estratégica, entre elas a análise ambiental e os modelos mentais, e, por isso, não elabora um planejamento eficiente para a sua manutenção no mercado. Tal fato pode ser confirmado pela fala do gestor entrevistado, quando afirmou que não utiliza nenhuma ferramenta, sistema, ou método para mapear o ambiente externo de sua empresa. Ao não realizar a análise ambiental, a qual permite o monitoramento do ambiente organizacional, o gestor não identifica as oportunidades e os riscos, atuais e futuros, que podem influenciar positiva ou negativamente a empresa no alcance de seus objetivos e de suas metas. 
Para esse gestor o ambiente externo se resume aos concorrentes provenientes de outras cidades e aos clientes que pertencem ao setor agrícola, predominante na região. Ele não menciona os demais componentes do ambiente operacional destacados por Andrade e Amboni (2007), que são os fornecedores, grupos reguladores, os demais stakeholders da empresa, produtos substitutos, dentre outros.

Através da análise do mapa mental, pode-se compreender a visão de ambiente do empresário do ramo de móveis planejados com atuação em Palmeira das Missões/RS. Entre as principais variáveis que estimulam as vendas da empresa, o empresário destacou serem os concorrentes, a produção agrícola que é a principal atividade econômica da região de atuação da empresa e as oportunidades de negócio com novas obras e construções. Em relação a principal variável a reduzir as vendas da empresa, o empresário salientou a crise econômica como a maior ameaça aos negócios. Portanto, o mapa mental é uma ferramenta que pode contribuir muito para a compreensão da complexidade presente no ambiente empresarial e na elaboração de estratégias das micro e pequenas empresas. O mapeamento mental apresentado possibilitou identificar o nível de conhecimento teórico sobre estratégia do entrevistado e a constatação de certas confusões na visão ambiental do estrategista, diante do posicionamento em relação ao ambiente que oscilou entre as perspectivas do ambiente objetivo, percebido e aprendido.

Entre as principais limitações do estudo, destacam-se a aplicação do estudo de caso em apenas uma empresa de pequeno porte do ramo de móveis planejados, assim como a realização de uma entrevista junto a um único participante. Existem outros métodos, técnicas e softwares de elaboração de mapas mentais ou sistêmicos que não foram explorados neste estudo.

Como sugestões para futuras pesquisas, salientam-se a possibilidade de estudos em empresas de médio e grande porte com maior número de participantes, além da classificação das abordagens estratégicas dentro das visões de ambiente objetivo, percebido ou construído. Sugere-se também o uso de outros métodos ou recursos de mapeamento mental no estudo acadêmico da estratégia ou mesmo na identificação de novas abordagens estratégicas organizacionais. 


\section{REFERÊNCIAS}

ANDRADE, A. L. et al. Pensamento sistêmico: caderno de campo. Porto Alegre: Bookman, 2006.

ANDRADE, R. O. B.; AMBONI, N. Teoria geral da administração: das origens às perspectivas contemporâneas. São Paulo: Makron Books, 2007.

ANSOFF, H. I. A nova estratégia empresarial. São Paulo: Atlas, 1990.

BARBOSA, F. J. M. et al. Visualização da informação e métodos visuais como ferramentas estratégicas para o gerenciamento de projetos. Revista de Gestão e Projetos, v. 9, n. 1, jan./abr. 2018.

BARNEY, J. B.; HESTERLY, W. S. Administração estratégica e vantagem competitiva. São Paulo: Pearson Prentice Hall, 2007.

CARVALHO, C. E. Relacionamento entre ambiente organizacional, capacidades, orientação estratégica e desempenho: um estudo no setor hoteleiro brasileiro. Tese de doutorado, UNIVALI, Biguaçu/SC: 2011. Disponível em: <http://www6.univali.br/tede/tde_busca/arquivo>. Acesso em: 11 set. 2015.

CERTO, S. C.; PETER, J. P.; CESAR, A. M. R. Administração estratégica: planejamento e implantação de estratégias. 3.ed. São Paulo: Pearson Education do Brasil, 2010.

CIDADE, I. G. N. et al. Modelos mentais como condicionantes do pensamento estratégico. v. 1, n. 1, p. 85-109, jan./jun. 2011. Disponível em: <http://www.publicacoesacademicas.uniceub.br/index.php/gti/article/download/1217/ 1091>. Acesso em: 11 set. 2015.

COSTA, B. K.; ALMEIDA, M. I. A. (Coord.). Estratégia: perspectivas e aplicações. São Paulo: Atlas, 2002.

CRAINER, S.; DEARLOVE, D. Estratégia: a arte e a ciência na criação e execução. Porto Alegre: Bookman, 2014.

DAFT, R. L.; WEICK, K. E. Organizações como sistemas interpretativos: em busca de um modelo. In: CALDAS, M. P.; BERTERO, C. O. (coord.) Teoria das organizações. São Paulo: Atlas, 2007. Cap. 11.

DONAIRES, O. S. Teoria geral de sistemas II. In: MARTINELLI, D. P.; VENTURA, C. A. A. Visão sistêmica e administração: conceitos, metodologia e aplicações. São Paulo: Saraiva, 2006.

DRUCKER, P. F. O melhor de Peter Drucker: a administração. São Paulo: Nobel, 2001. 
ERROBIDART, N. C. G. et al. Modelos mentais e representações utilizadas por estudantes do ensino médio para explicar ondas. Revista Electrónica de Enseñanza de las Ciencias, v. 12, n. 3, p. 440-457, 2013. Disponível em: <http://reec.uvigo.es/volumenes/volumen12/REEC_12_3_4_ex701.pdf>. Acesso em: 09 set. 2015.

LOBATO, D. M. et al. Estratégia de empresas. Rio de Janeiro: Editora FGV, 2003.

LUECKE, R. Estratégia (Harvard Business Essentials). 6.ed. Rio de Janeiro: Record, 2010.

MACIEL, C. O.; WEYMER, A. S. Q.; AUGUSTO, P. O. M. Identificando os Condicionantes Socialmente Construídos (Enacted) das Práticas Estratégicas em Ambientes Altamente Institucionalizados. Revista de Administração

Contemporânea - RAC, Rio de Janeiro, v. 16, n. 1, art. 5, p. 79-97, jan./fev. 2012.

MANKIW, G. Princípios de microeconomia. São Paulo: Cengage Learning, 2013.

MAXIMIANO, A. C. A. Introdução à administração. São Paulo: Atlas, 2008.

MINAYO, M. C. S. O desafio da pesquisa social. In: DESLANDES, S. F.; MINAYO, M. C. S. (Org.). Pesquisa social: teoria, método e criatividade. Petrópolis, RJ:

Vozes, 2009.

MINTZBERG, H.; AHLSTRAND, B.; LAMPEL. Safári de estratégia: um roteiro pela selva do planejamento estratégico. 2. ed. Porto Alegre: Bookman, 2010.

MONTELLA, M. Micro e macroeconomia. São Paulo: Atlas, 2012.

MOREIRA, M. A. Modelos mentais. Investigações em Ensino de Ciências, v. 1, n. 3, p. 193-232, 1996. Disponível em: <http://www.if.ufrgs.br/ienci/artigos/Artigo_ID17/ v1_n3>. Acesso em: 11 set. 2015.

MORGAN, G. Paradigmas, metáforas e resolução de quebra-cabeças na teoria das organizações. In: CALDAS, M. P.; BERTERO, C. O. (coord.) Teoria das organizações. São Paulo: Atlas, 2007. Cap. 2.

MOTTA, F. C. P.; VASCONCELOS, I. F. G. Teoria geral da administração. São Paulo: Pioneira, 2002.

NELLIS, J.; PARKER, D. Princípios de economia para os negócios. São Paulo: Futura, 2003.

OLIVEIRA, M. M. Como fazer pesquisa qualitativa. Petrópolis, RJ: Vozes, 2007.

PINDYCK, R. S.; RUBINFELD, D. L. Microeconomia. São Paulo: Pearson Education Brasil, 2010. 
SMIRCICH, L.; STUBBART, C. Strategic Management in an enacted world. Academy of Management Review, v. 10, n. 4, p. 724-738, 1985. Disponível em: <http://www.jstor.org/stable/258041?\&seq=2\#page_scan_tab_contents>. Acesso em: 28 set. 2015.

SIMON, H. A. Comportamento administrativo: estudo dos processos decisórios nas organizações administrativas. Tradução de Aluízio Loureiro Pinto. Rio de Janeiro: Fundação Getúlio Vargas, 1971.

Rational decision-making in business organizations. Pittsburgh, Pennsylvania, USA: Nobel Memorial Lecture, Carnegie-Mellon University, 1978.

SOUZA, A. L. C.; VENTURA, M. C. F. Mapas mentais como uma das ferramentas para o aumento da produtividade. Pesquisa Brasileira em Ciência da Informação e Biblioteconomia, João Pessoa, v. 12, n. 2, p. 111-120, 2017.

SOUSA, C. M. S. G. de; MOREIRA, M. A. A causalidade piagentiana e os modelos mentais: explicações sobre o funcionamento do giroscópio. Revista Brasileira de Ensino de Física, São Paulo, v. 22, n. 2, p. 223-231, jun. 2000.

TONI, D. D.; MILA, G.; HEXSEL, A. O desempenho organizacional a partir dos modelos mentais dos empreendedores: ... do setor metal-mecânico. In: ENCONTRO DE ESTUDOS EM ESTRATÉGIA, 3. 2007. São Paulo, SP. Anais eletrônicos... São Paulo, 2007. Disponível em: <http://www.anpad.org.br/diversos/ trabalhos/3E>. Acesso em: 09 set. 2015.

TONI, D. D. et al. Modelos mentais dos empreendedores e desempenho organizacional: um estudo ... do setor metal-mecânico. Porto Alegre, n. 15, jan./jun. 2014. Disponível em: <http://seer4.fapa.com.br/index.php/arquivo/article/view/194>. Acesso em: 09 set. 2015.

VERGARA, S. C.; CALDAS, M. Paradigma interpretacionista: a busca da superação do objetivismo funcionalista nos anos 1980 e 1990. In: CALDAS, M. P.; BERTERO, C. O. (coord.). Teoria das organizações. São Paulo: Atlas, 2007. Cap. 10.

ZACCARELLI, S. B. Estratégia e sucesso nas empresas. São Paulo: Saraiva, 2000.

Artigo recebido em: 24/01/2018

Artigo aprovado em: 08/04/2019

Artigo publicado em: 12/04/2019 